\title{
Research Protocol: Development, implementation and evaluation of a cognitive behavioural therapy-based intervention programme for the management of anxiety symptoms in South African children with visual impairments
}

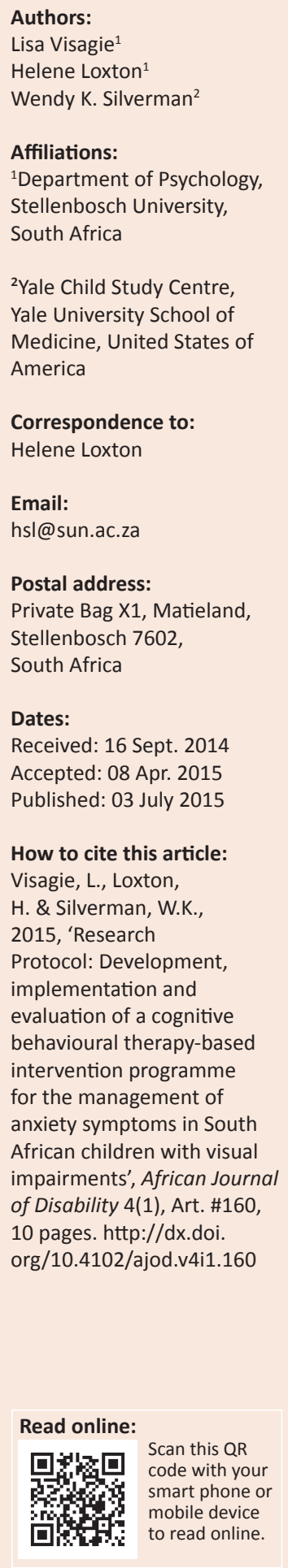

Background: Childhood anxiety presents a serious mental health problem, and it is one of the most common forms of psychological distress reported by youth worldwide. The prevalence of anxiety symptoms amongst South African youth is reported to be significantly higher than in other parts of the world. These high prevalence rates become even more significant when viewed in terms of children with visual impairments, as it is suggested that children with physical disabilities may be more prone, than their non-disabled peers, for the development of psychological difficulties.

Objectives: The main aim of this study is to develop, implement and evaluate a specifically tailored anxiety intervention programme for use with South African children with visual impairments.

Method: A specifically tailored cognitive-behavioural therapy-based anxiety intervention, for 9-13 year old South African children with visual impairments, will be evaluated in two special schools. The study will employ a randomised wait-list control group design with pre- postand follow-up intervention measures, with two groups each receiving a 10 session anxiety intervention programme. The main outcome measure relates to the participants' symptoms of anxiety as indicated on the Revised Child Anxiety and Depression Scale.

Conclusion: If the anxiety intervention programme is found to be effective in reducing symptoms of anxiety, this universal intervention will lay down the foundation upon which future contextually sensitive (South African) anxiety intervention programmes can be built.

\section{Introduction}

A substantial body of literature indicating that childhood anxiety presents a serious mental health problem has now been amassed (Barrett \& Turner 2001). Firstly, the literature indicates that anxiety is one of the most common forms of psychological distress reported by youth (Barrett \& Sonderegger 2005; Dadds et al. 1997). A recent meta analytic prevalence study indicated that an average of $12.3 \%$ of school-aged children (ages 6-12) experience significant symptoms of anxiety (e.g., Costello et al. 2011, 2003; Heiervang et al. 2007; McArdle, Prosser \& Kolvin 2004; Mullick \& Goodman 2005; Petersen et al. 2006). Secondly, although experiencing transient fears and anxieties is deemed to be a normal part of development for most children; for some these experiences may intensify and persist over time, causing interferences in daily functioning (Barrett, Lock \& Farrell 2005; Silverman 2011). Thirdly, the experience of childhood anxiety has been associated with a number of somatic difficulties such as fatigue, restlessness, irritability, and sleep disturbances (Beidel, Christ \& Long 1991; Pina \& Silverman 2004) and psychosocial impairments such as problems with peer relations, low self-esteem, immaturity, impaired academic functioning, and concentration problems (Cooley, Boyd \& Gratos 2004; Farrell \& Barrett 2007; Messer \& Beidel 1994; Motoca, Williams \& Silverman 2012). Fourthly, if left untreated, severe symptoms of anxiety can take on a chronic and unremitting course (Barrett \& Turner 2004; Cole et al. 1998; Weems \& Silverman 2013), and many adults who are diagnosed with an anxiety disorder can trace the onset of symptoms back to their childhood (Rapee \& Barlow 1993). Given this suggested relationship between childhood anxiety and adult psychopathology, it is essential for symptoms of anxiety to be addressed as early as 
possible (Cobham 2003), and promising in this regard is the increased evidence pointing to the amenability of childhood anxiety symptoms to brief psychosocial interventions (Lowry-Webster, Barrett \& Dadds 2001; Silverman, Pina \& Viswesvaran 2008).

Yet, despite these promising results, research indicates that less than $20 \%$ of children who require treatment for anxiety will receive clinical intervention (Day \& Roberts 1991; Olfsen et al. 2003), and of those who do, a large number will terminate prematurely (Kazden 1996; Pina et al. 2003), fail to respond (Donovan \& Spence 2000; Rey, Marin \& Silverman 2011) or, despite treatment, continue to experience recurrent difficulties (Last et al. 1996).

In addition, long waiting lists, high costs, high instances of family drop outs, and no show rates also influence access to treatment (Weist 1999). As a result, health policies across the world increasingly promote prevention as the most important direction in which mental health services should move (Barrett \& Turner 2004; Lowry-Webster, Barrett \& Lock 2003). Prevention offers a positive adjunct to treatment, as prevention programmes can reach a large number of individuals over a shorter period of time; avoid high levels of personal distress for children and their families; and offer a cost-effective and efficient means of intervention prior to the onset of psychopathology (Farrell \& Barrett 2007).

The South African prevalence rates of anxiety symptoms are even higher than the above-mentioned international estimates suggest, with Muris and his colleagues (Muris et al. 2002) reporting prevalence rates of anxiety symptomology between $22 \%-25.6 \%$ in children aged 7 to 13 years. These findings were confirmed in subsequent South African studies (Burkhardt, Loxton \& Muris 2003; Muris et al. 2006). Mostert and Loxton (2008) noted these high prevalence rates and identified the need for a suitable anxiety intervention programme which could be implemented within the South African context. Previous international studies and also the World Health Organization (WHO 2004) had identified Barrett's (2004) cognitive behavioural therapy (CBT) based FRIENDS Programme to be an efficacious intervention for the reduction of anxiety symptoms in youth (see Briesch, Hagermoser Sanetti \& Briesch [2010] for an overview). As a result, Mostert and Loxton (2008) conducted a pilot study to explore the effectiveness and suitability of the FRIENDS Programme for use with South African children. This study reported promising results and its outcomes were in line with the government's white paper on the transformation of the South African health care system, as the study promoted prevention as an important strategy for the enhancement of the mental and physical health of the nation (DOH 1997).

The above-mentioned anxiety factors, their high prevalence rates, and identified need for a suitable intervention programme, become even more significant when viewed in terms of the population of children with visual impairments, who are often marginalised, as previous research involving children with physical disabilities suggests that they are at increased risk of developing psychological difficulties when compared to their non-disabled peers (see Gullone [1996] for an overview). Despite this identified risk, this population has been neglected in previous fear and anxiety research. The last international study to touch on this topic was conducted by Weimer and Kratochwill more than two decades ago (1991) in Wisconsin (USA).

Identifying this gap in the literature, the authors (Visagie et al. 2013) conducted an exploratory (baseline) study with South African children with visual impairments. Results indicated that the overall fear profiles of children with visual impairments, and children with normal sight, did not differ significantly (Visagie et al. 2013). This similarity indicates that the two populations (children with and children without visual impairments) have similar needs. As the need for a suitable anxiety intervention programme was highlighted in the general South African population (children without visual impairments) (Burkhardt et al. 2003; Mostert \& Loxton 2008; Muris et al. 2006), the same can be said for this specific group. Children with visual impairments also require a suitable and accessible anxiety intervention programme (Loxton, Visagie \& Ollendick 2012; Visagie et al. 2013).

On closer evaluation of the study by Visagie et al. (2013), the need for a suitable anxiety intervention programme was noted to be especially prominent for a specific sub-group of children with visual impairments (i.e. children with severe visual impairment). In their 2012 paper Loxton, Visagie and Ollendick (2012) highlighted significant differences in fearfulness between three groups of visually impaired children who had varying levels of sight (i.e. partially sighted, severely visually impaired and totally blind). These levels of vision can be viewed on a sliding scale (i.e. children who are partially sighted have the most vision; children with severe visual impairment have less vision, but they are not totally blind; and the totally blind children have no level of measureable vision). Children with severe visual impairment (i.e. children who have a degree of light perception and movement detection, but who cannot function optimally without assistance and cannot read print material (WHO 2000), were more fearful than the partially sighted and totally blind children. This group reported the highest number $(\mathrm{M}=42.09, \mathrm{SD}=17.84)$ and also level $(\mathrm{M}=171.63, \mathrm{SD}=28.60)$ of fear. This reported number of fears is almost double the number reported by the children with normal sight $(\mathrm{M}=24.66, \mathrm{SD}=13.12)$. The level of fear in children with normal sight was also lower $(\mathrm{M}=146.15, \mathrm{SD}=25.33)$.

Thus, children with severe visual impairment can be identified as a high-risk sub-group within the broader population of children with visual impairments, for the possible development of later anxiety disorders. A possible suggestion for this sub-group's greater instance of fearfulness could relate to the fact that the visual difficulties, of this group of children, are the most differentiated and difficult to understand. The totally blind children can see nothing; therefore, they need assistance in most unfamiliar situations. On the other hand, partially sighted children 
usually have enough sight to help themselves and move around independently, and the children with severe visual impairment are in the middle, this group's visual difficulties may be the most complex and most disabling.

Although children with severe visual impairments have a degree of measurable vision, they may find it difficult to function independently in an unfamiliar environment. Therefore, the uncertainty when they are faced with new situations and possibilities may contribute directly to their higher fear reactivity (Bensch 2010; Loxton et al. 2012; Sacks et al. 2006; Visagie et al. 2013). Therefore, it is essential for these children to have access to suitable intervention programmes focused on the development of appropriate coping strategies and problem solving skills to enable them to deal competently with anxiety symptoms when they arise.

Although Mostert and Loxton (2008) obtained favourable outcomes with the FRIENDS Programme with a group of South African children, their study did incur some limitations. It was noted that the FRIENDS acronym ( $F$ for feeling worried?, R for Relax and feel good, I for Inner thoughts, E for Explore plans of action, N for Nice work, reward yourself!, $\mathrm{D}$ for Do not forget to practise, and lastly $\mathrm{S}$ for Stay cool and calm! (Barrett 2004, cited in Mostert 2007), which is aimed to aid children in remembering the coping steps to take when faced with a problem, was difficult for some South African children to remember and problematic to translate into Afrikaans (Mostert \& Loxton 2008). Furthermore, Mostert and Loxton (2008) concluded that although the FRIENDS Programme has been used successfully in other countries, South African socio-contextual issues (the high incidence of crime and poverty) should not be ignored - research should in addition be focused on constructing a socially relevant anxiety intervention programme that considers the impact of these factors (Mostert \& Loxton 2008). In addition, the FRIENDS Programme is not suitable for use with children with visual impairments, as its content (i.e. cartoons, colouring-in pictures, workbook and visual-based activities) is not very accessible to this specific population.

To summarise, the following six factors motivated the proposed study:

- The high prevalence rates of anxiety symptomology in the general population (especially in South Africa)

- The suggestion that visually impaired children are at increased risk for the development of anxiety disorders when compared to their sighted counterparts

- The lack of anxiety research involving children with visual impairments

- The unique South African socio-cultural context

- The benefits associated with prevention and early intervention with regards to childhood anxiety

- The inaccessibility and appropriateness of existing anxiety intervention programmes.

As a result, the proposed study will aim to develop, implement and evaluate an anxiety prevention or early intervention programme (from here on referred to as an anxiety intervention programme), which is specifically tailored to meet the needs of children with visual impairments within the South African context. As far as the researchers can ascertain, no studies focussed on anxiety prevention and early intervention programmes, for children with visual impairments, have been conducted previously.

Thus, the primary aim of the study is to develop, implement and evaluate a specifically tailored anxiety intervention programme for use with South African children with visual impairments. This aim will unfold in the following three steps:

1. develop an accessible anxiety intervention programme which can be used with South African children with visual impairments (programme development phase).

2. implement this anxiety intervention programme successfully (programme implementation phase).

3. evaluate the effectiveness of this anxiety intervention programme in maintaining emotional health (i.e. preventing an increase in symptoms of anxiety as measured on the Revised Child Anxiety and Depression Scale [RCADS] [Chorpita et al. 2000] [programme evaluation phase]).

Specifically, it is expected that firstly, there will be a significant reduction in anxiety scores on the RCADS from Time 1 (T1) to Time 2 (T2) for the immediate intervention group (IIG), and secondly, there will be a significant reduction in anxiety scores on the RCADS from T2 to T3 for the delayed intervention group (DIG).

\section{Method}

A specifically tailored CBT-based anxiety intervention for South African children with visual impairments will be evaluated in two special schools that cater for children with visual impairments. This study is set up as a randomised wait-list control group design with pre-, post-and followup intervention measures, with 60 participants randomly assigned to an IIG $(n=30)$ and a DIG $(n=30)$. Before implementation of the programme 10 participants from each group will be randomly selected to take part in a focus group. The focus group will be aimed at obtaining the participants' personal inputs and to pilot certain sections of the programme before final implementation. Both of the programme's groups will receive the 10 session anxiety intervention programme. The participants will complete baseline (T1), post intervention (T2 for IIG and T3 for DIG) and 3 month (T3 for IIG and T4 for DIG) or 6 month (T4 only for IIG) follow-up assessments.

The research design can be represented as follows:

$\begin{array}{lllllll}\mathrm{R} & \text { IIG T1 } & \mathrm{X} & \text { IIG T2 } & & \text { IIG T3 } & \text { IIG T4 } \\ \mathrm{R} & \text { DIG T1 } & & \text { DIG T2 } & X & \text { DIG T3 } & \text { DIG T4 }\end{array}$

$\mathbf{R}=$ Randomisation

$\mathrm{X}=$ intervention 


\section{Participants}

It is envisaged that the final sample will consist of approximately 60 children; 30 children in the IIG and 30 children in the DIG who attend Grades 4-7 (aged 9-13 years) at two schools (School 1 and School 2), for children with visual impairments in the Western Cape Province of South Africa. Letters explaining the study will be sent to the two identified schools, and the necessary written consent for participation will be requested from the school principals and school governing bodies.

Parents or guardians of the identified participants (children attending Grades 4-7) will be provided with an information letter explaining the study and a consent form giving their child permission to take part. Identified participants will also be provided with information about the study and they will be required to give written assent before they are delivered the programme. Thus, dual parent-child consent and assent will be required for inclusion. This study received approval (HS888/2013) from the Research Ethics Committee: Human Research (Humaniora) at the Stellenbosch University (Institutional Review Board Number: IRB0005239), and the Western Cape Education Department in South Africa (Reference: 20130507-10635).

\section{Inclusion criteria}

The criterion for inclusion in the study will be one of universal prevention where children will be included in the programme regardless of their anxiety status. Universal prevention is a positive approach to social-emotional learning as it aims to build strengths in all children through the enhancement of known skills and protective factors (Farrell \& Barrett 2007). However, a distinction about the programme description can be made. Based on each participants T-score on the RCADS (Chorpita et al. 2000) at T1, the programme can be described as either an early intervention (T-score above 65) or prevention programme (absence of significant symptoms of anxiety). Furthermore, participants should be aged between 9 and 13 (attend Grades 4-7), and be able to read and write. The reason for this requirement is that the measuring instruments are self-report surveys and participants must read the questions and complete these themselves. Lastly, with the exception of visual impairment, participants included in the study should have no other disability.

\section{Randomisation}

Randomisation will be applied within schools with an immediate intervention and delayed intervention group within each school. Participants will be assigned to either the IIG or the DIG at their respective schools. The IIGs from School 1 and School 2 will be combined to form one large IIG, and the DIGs from School 1 and School 2 will be combined to form one large DIG.

\section{Programme intervention}

A specifically tailored, group-based, anxiety intervention programme for children with visual impairments will be implemented as a universal intervention. The anxiety intervention programme, which is based on a CBT model, was developed over a period of six months. CBT-based interventions employ both cognitive (e.g. positive self-talk) and behavioural (e.g. relaxation) techniques to modify cognitions, behaviour and affect (Kendall 1993; Nevid, Rathus \& Green 2000; Silverman \& Kurtines 1996). Thus, CBT-based interventions aim to teach children to identify maladaptive thoughts and to replace these thoughts with more positive ones (Mash \& Wolf 2005). In addition, one of the greatest benefits of CBT is its longevity, as CBT is focussed on equipping people with a set of coping skills that can be used both now and in the future. Furthermore, CBT-based interventions are usually shorter-term interventions, making them more cost-effective and appealing (Farrell \& Barrett 2007; Ollendick \& King 1998; Silverman et al. 2008). For these reasons, CBT was the intervention modality of choice for the study.

The eight key concepts of CBT as described by Barrett and Turner (2001) are central to the anxiety intervention programme's theoretical base, and include:

1. recognition of the link between thoughts and feelings

2. identifying feelings

3. relaxation strategies

4. cognitive restructuring

5. attention training

6. problem-solving

7. self-reward

8. relapse prevention.

The programme's core theme relates to the enhancement and development of skills or competencies which can be employed when confronted with difficult situations, whether they relate to fears or worries, daily hassles (e.g. struggling with a difficult homework assignment), or stressful and aversive life events (e.g. moving to a different school or facing family conflict) (Barrett \& Turner 2001). In addition to incorporating the eight key concepts of CBT, the anxiety intervention programme lent and built on ideas and concepts adapted from already existing CBT-based approaches and programmes, such as:

- Kendall's Coping Cat Programme (Kendall 1990)

- Barrett's Coping Koala Programme (Barrett 1995)

- Silverman and Kurtine's Transfer of control approach (Silverman \& Kurtines 1996)

- Stallard's Think Good-Feel Good Programme (Stallard 2002)

- Barrett's FRIENDS For Life Programme (Barrett 2004)

- Rapee's Cool Kids ${ }^{\circledast}$ Programme (Rapee et al. 2006).

The challenge in this adaptation was not only to translate the eight key concepts of CBT into a child-friendly and age-appropriate programme, aimed at combating anxiety symptoms, but also to present the programme in a format that is accessible and appealing to children with visual impairments. As an alternative to reading and colouring in pictures (which is the norm in most of the programmes to date) 
the adapted programme makes use of clay (and other tactile media), toys, role-plays, games, songs, narratives and other creative techniques as alternative forms of engagement. As the FRIENDS acronym is not suitable for use in the proposed study the title for the adapted intervention programme is the P\&M programme (PAM = Positive \& Motivating, and in Afrikaans Positief \& Motiverend). Activities in the P\&M programme are aimed at teaching children with visual impairments practical skills, such as: identifying feelings; relaxation skills; identifying unhelpful and helpful thoughts; and how to deal with daily problems and challenges (Stallard et al. 2007).

\section{Immediate intervention group (IIG)}

All assenting children in the IIG will receive a 10-session CBT-based, group programme, each session will last approximately 60 minutes. The sessions will take place twice a week for five weeks. Groups consist of 8-10 participants. The programme will be delivered at schools during a time negotiated with the school. The Programme will start with activities that promote group cohesion and teamwork (session 1). In sessions 2 and 3 psycho-education, regarding emotions and thoughts, is given, and in session 4 bodily reactions to anxiety are addressed and relaxation exercises are introduced. Group participants are encouraged to practice these relaxation exercises throughout the duration of the programme. The next step (session 5) relates to recognising inner thoughts and the promotion of positive thinking. Session 6 introduces the concept of cognitive restructuring and introduces participants to problem solving skills. Self-evaluation and reinforcement is introduced in session 7. Sessions 8 and 9 allow for group participants to repeat and practice the new skills they have learnt, and session 10 covers relapse prevention and there is a party to celebrate the completion of the programme. At the start of the programme, parents or guardians and teachers will also be invited to attend an additional psycho-educational information session. This information session will provide an overview of the anxiety intervention programme, discuss the rationale underlying CBT-based programmes and explain the skills that children will be taught.

\section{Delayed intervention group (DIG)}

Participants in the DIG will be delivered the same intervention programme straight after the programme has been delivered to participants in the immediate intervention group, and they will also be asked to complete three questionnaires on four occasions, together with the children in the IIG.

\section{Group leader (Trainer)}

The programme will be delivered by the first author and a research facilitator (a post-graduate student in psychology) in either English or Afrikaans, depending on the children's language of schooling. The first author is a registered counselling psychologist with ample experience and knowledge relating to developmental psychology and CBT.
The group leader will be blind to all assessment measures. The reason the first author herself will conduct the intervention is that there are no other qualified psychologists available who are visually impaired, and who are attuned to the social and cultural context of the participants.

\section{Programme evaluation}

As mentioned above, all assenting children from School 1 and School 2 will randomly be assigned to 1 of 2 groups at their respective school (an IIG or a DIG). The IIG groups from School 1 and School 2 will be combined to form one large IIG, whilst the DIG groups from School 1 and School 2 will be combined to form one large DIG.

The evaluation phase will comprise both a quantitative and qualitative component (more information about the qualitative component is given below). For the quantitative evaluation, all assenting children in the IIG and DIG (approximately 60 participants) will be administered a short biographical questionnaire (only at T1) and three self-report questionnaires at pre (T1), post (T2), and follow-up (T3 and T4) intervention. Children in the IIG will receive the intervention programme before the children in the DIG. It is envisaged that the programme will be delivered to the two groups (the IIG and DIG) of children according to the following outline:

- Initial assessment of all children, IIG and DIG (T1)

- Children in the IIG receive the anxiety intervention programme (5 weeks)

- Re-assessment of all children, IIG and DIG (T2)

- Children in the DIG receive the anxiety intervention programme (5 weeks)

- Re-assessment of all children, IIG and DIG (T3)

- Final assessment of all children, IIG and DIG (T4 - It will be 6 months after the children in the IIG received the intervention and 3 months after the children in the DIG received the intervention). Resulting from time constraints, where all assessments should be conducted within one academic year, there will be no 6 month follow-up for the DIG, and no wait period for the IIG.

It will be possible to measure:

- The stability of the measures when untreated over time (The DIG will act as a wait-list control group using T1 and T2 comparisons)

- The impact of the anxiety intervention programme immediately after completion (using immediate pre and post-data from both groups - IIG [T1 and T2]; and DIG [T2 and T3])

- The maintenance of the effects of the anxiety intervention programme over time following intervention (IIG using T2, T3 [3 month] and T4 [6 month] comparisons, and DIG using T3 and T4 [3 month] comparisons)

The following six hypotheses are to be tested during the evaluation phase of the proposed study (four hypotheses pertain to between group effects and two hypotheses pertain to within group effects). 


\section{Between group effects}

- Firstly, it is hypothesised that there will be no significant differences between the scores obtained by the IIG and DIG on the RCADS at T1.

- Secondly, anxiety scores obtained by the IIG on the RCADS (post intervention) will be significantly lower than the anxiety scores obtained by the DIG on the RCADS at T2.

- Thirdly, there will be no significant differences in the anxiety scores of the IIG at T2 and DIG on the RCADS at T3.

- Fourthly, results obtained on the RCADS at postintervention (T3) will be retained at the three (DIG) and six month (IIG) follow-ups (T4).

\section{Within group effects}

- Within the IIG there will be a significant reduction in anxiety scores on the RCADS from T1 to T2.

- Within the DIG there will be a significant reduction in anxiety scores on the RCADS from T2 to T3.

For the qualitative process evaluation of the programme, all ten intervention sessions will be video recorded, and the verbal content of the recordings will be transcribed verbatim. The transcriptions will be analysed to identify recurring themes (thematic content analyses). After completion of the ten sessions participants will also be asked to complete a series of short questions compiled by the researcher. In addition, the researcher and the research assistant (observer) will also keep a detailed record (in the form of process notes) of all sessions. The intervention programme will be completely manualised and a quantifiable measure, to measure adherence to the treatment protocol, will be developed and implemented. These qualitative components will be included in the research to ensure fidelity and to provide as many pointers as possible to aid in the understanding of an underresearched problem, namely anxiety experienced by children with visual impairments.

Hartley and Muhit (2003) state that the inclusion of a qualitative component in research can help bridge the gap between scientific study and clinical practice, and may assist in gaining a better understanding of the phenomena under investigation. They further argue that qualitative methodology is needed to collect cultural and disability specific data which may not be easily obtained through quantitative methods, as the low prevalence rates of some disabilities make it very difficult to draw statistically significant conclusions from quantitative data (Philander 2007). Hartley and Muhit (2003:103) further emphasise that qualitative sources of data provide an opportunity not only to listen, but also to include the voices of vulnerable populations in programme planning. They stated this as follows: 'it [qualitative data] educates quantitative researchers about the people and their perceptions, beliefs and practices'.

\section{Data collection}

Questionnaires will be made available in four different input modes relating to the individual participant's specific needs and degree of visual impairment. In some cases the original print versions of the questionnaires will be provided and read by means of a magnifying aid, questionnaires will also be put in a large print format (A3), and for those participants who cannot read print, the questionnaires will be made available in braille or in an audio format. The modes of response will also be adapted to suit the individual participant's communication needs. Participants who are able to read the standard or large print copies of the questionnaires can indicate their answers in the spaces provided, and for the participants using braille or recorded versions of the questionnaires, specially prepared answer sheets will be made available.

In previous studies (King, Gullone \& Stafford 1990; Matson et al. 1986; Ollendick, Matson \& Helsel 1985; Wilhelm 1989) where the fears and anxieties of visually impaired children were assessed using self-report measures (e.g. The Revised Fear Survey Schedule for Children, FSSC-R; The South African Fear Survey Schedule for Children, FSSCSA; and the Revised Children's Manifest Anxiety Scale, RCMAS) similar adaptations were made with great success. Children will complete the questionnaires at their school with the help of the research facilitators. Guidelines put forth by Visagie and Loxton (2014) about the child-friendly assessment and the accomodations needed for children with visual impairments to complete self-report surveys, will be implemented and followed throughout the process of data collection.

The questionnaires will be administered to all participants (IIG and DIG) on four occasions:

- Immediately before delivering the anxiety intervention programme to the IIG (T1) (Baseline)

- Immediately after delivering the anxiety intervention programme to the IIG, and before delivering the anxiety intervention programme to the DIG (T2)

- Immediately after delivering the anxiety intervention programme to the DIG (T3)

- At follow-up, six months after delivering the programme to the IIG, and three months after delivering the programme to the DIG (T4)

\section{Participant outcomes}

The primary outcome measure in the study relates to changes in levels of symptoms of anxiety and depression on the Revised Child Anxiety and Depression Scale (RCADS) (Chorpita et al. 2000). The 30 items of the RCADS assess symptoms across six domains of anxiety and depression in children (aged 6-18), including:

- social phobia

- separation anxiety

- obsessive compulsive disorder 
- panic disorder

- generalised anxiety disorder

- major depressive disorder.

Items are rated on a four-point Likert scale. Psychometric properties of the RCADS are good; the six RCADS scales were found to have adequate internal consistency (with all alphas in the .70 and .80 range) and test-retest stability (with one-week test-retest correlation coefficients ranging from .65 to .80) (Chorpita et al. 2000; Muris, Meesters \& Schouten 2002). The RCADS is freely available on the Internet for download, and permission to translate the questionnaire into Afrikaans was obtained from the authors. Translations were written by a registered clinical psychologist who is fluent in both English and Afrikaans in accordance with the Brislin (1980) back-translation method.

Secondary outcome measures relate to children's worry and self-efficacy measured by the Penn State Worry Questionnaire for Children (PSWQ-C) (Chorpita et al. 1997) and SelfEfficacy Questionnaire for Children (SEQ-C) (Muris 2001) respectively. The PSWQ-C (Chorpita et al. 1997) is an 11-item questionnaire which assesses the tendency of children (aged 7-17) to engage in excessive generalised and uncontrolled worry. Respondents are asked how often each item applies to them by indicating answer options on a four-point Likert scale. Chorpita et al. (1997) found the PSWQ-C to have favourable psychometric properties, reporting good internal consistency $(A=.88)$ and test-retest reliability $(R=.92)$ (over a one-week interval). The PSWQ-C is freely available on the Internet for download, and permission was obtained from the authors to translate the questionnaire into Afrikaans. Once again translations were written in accordance with the Brislin (1980) back-translation method. Muris's (2001) SEQ-C is a 24 item self-report scale. The SEQ-C measures children's self-efficacy across three domains including: social, academic and emotional self-efficacy. Respondents are required to rate each of the 24 items on a five-point Likert scale. The reliability of the scale ranges from .88 for total self-efficacy and between .85 and .88 for the three sub-scales (Muris 2001). The SEQ-C has been translated into Afrikaans and has been used successfully in previous studies (Le Roux 2013; Muris 2001).

\section{Teacher outcomes}

An additional outcome relates to emotional and behavioural difficulties experienced by group participants. The Strengths and Difficulties Questionnaire (SDQ) is a widely used, brief behavioural screening questionnaire aimed at detecting behavioural and emotional difficulties in youth (aged 3-16 years) (Mostert 2007). The SDQ consists of 25 items which can be divided into five sub-scales of five items each. Four sub-scales comprise the most important domains of child psychopathology, including:

- emotional symptoms

- conduct problems

- hyperactivity and inattention

- peer relationship problems.
Scores on these sub-scales add up to a total difficulties score. The remaining subscale (pro-social behaviour) measures the child's strengths in social interactions (Goodman 1997). Items are scored on a three-point Likert scale (Goodman et al. 2003). Class teachers will be asked to complete the informant version of the SDQ (Mostert 2007) on two occasions for each participant, before and directly after implementation of the anxiety intervention programme. The informant version of the SDQ assesses the teacher's perception of whether a child has a problem or not. Focus is given to chronicity, distress, social impairment and burden. The SDQ has been found to have favourable psychometric properties and the questionnaire was deemed to have good construct validity, as it was found to have substantial correlations with other indices of psychopathology (Goodman, Meltzer \& Bailey 1998; Goodman, Renfrew \& Mullick 2000; Goodman et al. 2003).

\section{Qualitative outcomes}

The final outcome measure relates to the qualitative evaluation of the programme. It is not only important to determine whether a programme works, but also whether the participants consider the programme to be beneficial and worthwhile (Barrett \& Turner 2001). For this reason, after completion of the 10 sessions, oral instructions will be given to participants to complete a series of short questions compiled by the researcher. These questions provide an opportunity to obtain qualitative feedback from the participants relating to their experience of, and satisfaction with, the anxiety intervention programme.

\section{Statistical analyses}

The Statistical Package for the Social Sciences (SPSS) (Van Leeuwen et al. 2006) will be used to calculate descriptive and non-parametric statistics. As a result of the envisaged small sample size $(N=60)$, a Mann-Whitney test will be used to determine the significance of differences between the quantitative pre-and-post intervention measures (George \& Mallery 2006). Pre-intervention (T1) scores will be analysed to determine the equivalence of the IIG and the DIG, before the intervention and change scores (difference between the pre-and post-intervention scores) for the IIG and DIG will be compared to evaluate change as a result of the intervention programme. Qualitative data will be analysed by means of thematic content analyses.

\section{Discussion}

This study will employ a randomised wait-list control group design with pre and post-intervention measures to evaluate the effectiveness of a specifically tailored, groupbased, CBT anxiety intervention programme for 9-13 year old South African children with visual impairments. It is hypothesised that children in the IIG will experience significantly reduced symptoms of anxiety when compared to children in the DIG. 


\section{Strengths and limitations}

The major strength of this study is that it is the first of its kind, with no studies focussed on anxiety prevention and early intervention programmes for children with visual impairments having been conducted previously. Thus, this research has a novel methodology and it will fill an important gap in the literature by developing and promoting critically needed, specifically tailored anxiety prevention strategies which can be used by children with visual impairments. Expected advantages for participants include:

- a reduction in anxiety symptomology

- an increase in self-efficacy

- the acquisition of helpful problem solving skills and coping strategies.

Thus, the programme is aimed at optimising human development and, in this way, contributing to future wellbeing and potentially reducing the prevalence of anxiety in the population of children with visual impairments. Rather unique to the study's design is the qualitative feedback from the participants and facilitators relating to their experience of and satisfaction with the anxiety intervention programme. These qualitative data will provide muchneeded information to aid in the understanding of an underresearched problem, namely anxiety experienced by children with visual impairments.

One limitation is the study's small sample size. This is the result of logistical and geographical constraints. South Africa is a large country and schools for children with visual impairments are widely dispersed which, thus, limits the author's capacity to travel to numerous schools on a weekby-week basis.

\section{Implications for practice}

If it is found that this anxiety intervention programme is effective in reducing symptoms of anxiety in South African children with visual impairments, this group-based universal intervention will lay down the foundation upon which future contextually sensitive (South African) anxiety intervention programmes can be built. Furthermore, a recent article by Lyner-Cleophas et al. (2014) highlighted the importance of developing coping skills at an early age for academic success later in life.

\section{Conclusion}

This study will evaluate the effectiveness of a specifically tailored, group-based, CBT anxiety intervention programme for South African children with visual impairments, and the results rendered by the study will provide insights into the effectiveness of the anxiety intervention, and determine its suitability for future use within the South African context.

\section{Acknowledgements}

The authors would like to thank Professors Leslie Swartz (Stellenbosch University) and Prof Paul Stallard (Bath
University) for their invaluable comments and insights throughout the process of drafting this manuscript with regard to the proposed study. The financial assistance of the National Research Foundation (NRF), South Africa as well as the Fulbright scholarship program towards this research is hereby acknowledged. Opinions expressed and conclusions arrived at, are those of the authors and are not necessarily to be attributed to the NRF or the Fulbright scholarship program.

\section{Competing interests}

The authors declare that they have no financial or personal relationships which may have inappropriately influenced them in writing this article.

\section{Authors' contributions}

L.V. (Stellenbosch University) will carry out the study and she drafted the initial manuscript. Both L.V., H.L. (Stellenbosch University) and W.K.S. (Yale University School of Medicine) critically revised the manuscript and approved the final draft. W.K.S. contributed to the study's design by suggesting the addition of the focus groups.

\section{References}

Barrett, P.M., 1995, Group coping koala workbook, unpublished manuscript, School of Applied Psychology, Griffith University, Australia.

Barrett, P.M., 2004, FRIENDS for life: Group leader's manual, Australian Academic Press, Brisbane.

Barrett, P.M., Lock, S. \& Farrell, L.J., 2005, 'Developmental differences in universal preventive intervention for child anxiety', Clinical Child Psychology and Psychiatry 10(4), 539-555. http://dx.doi.org/10.1177/1359104505056317

Barrett, P.M. \& Sonderegger, R., 2005, 'Anxiety in children - FRIENDS program', in A. Freeman, S.H. Felgois, C.M. Nezu \& A.M. Reinecke (eds.), Encyclopedia of cognitive behaviour therapy, 2nd edn., Springer. http://dx.doi.org/10.1007/0306-48581-8_14

Barrett, P.M. \& Turner, C., 2001, 'Prevention of anxiety symptoms in primary school children: Preliminary results from a universal school-based trial', British Journal of Clinical Psychology 40(4), 399-410. http://dx.doi.org/10.1348/014466501163887

Barrett, P.M. \& Turner, C.N., 2004, 'Prevention of childhood anxiety and depression' in P.M. Barett \& T.H. Ollendick (eds.), Handbook of interventions that work with children and adolescents, pp. 429-474, West Sussex, Wiley. http://dx.doi. org/10.1002/9780470753385.ch18

Beidel, D.C., Christ, M.G. \& Long, P.J., 1991, 'Somatic complaints in anxious children', Journal of Abnormal Child Psychology 19(6), 659-670. http://dx.doi.org/10.1007/ BF00918905

Bensch, L.S., 2010, 'A comparative study of fears in middle-childhood South African children with and without visual impairments', Masters thesis, University of Stellenbosch.

Briesch, A.M., Hagermoser Sanetti, L.M. \& Briesch, J.M., 2010, 'Reducing the prevalence of anxiety in children and adolescents: An evaluation of the evidence base for the FRIENDS for life programme', School Mental Health 2(4), 155-165. http://dx.doi.org/10.1007/s12310-010-9042-5

Brislin, R.W., 1980, 'Back-translation for cross-cultural research', Journal of CrossCultural Psychology 1, 185-216. http://dx.doi.org/10.1177/135910457000100301

Burkhardt, K., Loxton, H. \& Muris, P., 2003, 'Fears and fearfulness in South African children', Behaviour Change 20(2), 94-102. http://dx.doi.org/10.1375/ bech.20.2.94.24837

Chorpita, B.F., Tracey, S.A., Brown, T.A., Collica, T.J. \& Barlow, D.H., 1997, 'Assessment of worry in children and adolescents: An adaptation of the Penn State Worry Questionnaire', Behaviour Research and Therapy 35(6), 569-581. http://dx.doi. org/10.1016/S0005-7967(96)00116-7

Chorpita, B.F., Yim, L., Moffitt, C., Umemoto, L.A. \& Francis, S.E., 2000, 'Assessment of symptoms of DSM-IV anxiety and depression in children: A revised child and anxiety scale', Behaviour Research and Therapy 38(8), 835-855. http://dx.doi. org/10.1016/S0005-7967(99)00130-8

Cobham, V., 2003, 'Evaluation of a brief child-focused group-based intervention for anxiety-disordered children', Behaviour Change 20(2), 109-116. http://dx.doi. org/10.1375/bech.20.2.109.24838

Cole, D.A., Peeke, L.G., Martin, J.M., Truglio, R. \& Seroczynski, A.D., 1998, 'A longitudinal look at the relation between depression and anxiety in children and 
adolescents', Journal of Consulting and Clinical Psychology 66(3), 451-460. http:// dx.doi.org/10.1037/0022-006X.66.3.451

Cooley, M.R., Boyd, R.C. \& Gratos, J.J., 2004, 'Feasibility of an anxiety preventive intervention for community violence exposed African-American children', The Journal of Primary Prevention 25(1), 105-123. http://dx.doi.org/10.1023/ B:JOPP.0000039941.85452.ea

Costello, E.J., Egger, H.L., Copeland, W., Erkanli, A. \& Angold, A., 2011, 'The developmental epidemiology of anxiety disorders: Phenomenology, prevalence, and comorbidity', in W.K. Silverman \& A.P. Field (eds.), Anxiety disorders in children and adolescents, 2nd ed., Cambridge University Press. http://dx.doi.org/10.1017/ CBO9780511994920.004

Costello, E.J., Mustillo, S., Erkanli, A., Keeler, G. \& Angold, A., 2003, 'Prevalence and development of psychiatric disorders in childhood and adolescence', Archives of General Psychiatry 60(8), 837-844.

Dadds, M.R., Spence, S.H., Holland, D.E., Barett, P.M. \& Lawrens, K.R., 1997 'Prevention and early intervention for anxiety disorders: A controlled trial', Journal of Consulting and Clinical Psychology 65(4), 627-635. http://dx.doi. org/10.1037/0022-006X.65.4.627

Day, C. \& Roberts, M.C., 1991, 'Activities of the children and adolescent service system program for improving mental health for children and families', Journa of Clinical Child Psychology 20(4), 340-350. http://dx.doi.org/10.1207/ s15374424jccp2004_2

Department of Health (DOH), 1997, White paper for the transformation of the health system in South Africa, viewed 27 August 2012, from http://www.info.gov.za/ whitepapers/1997/health.htm

Donovan, C.L. \& Spence, S.H., 2000, 'Prevention of childhood anxiety disorders', Clinical Psychology Review 20(4), 509-531. http://dx.doi.org/10.1016/S0272 7358(99)00040-9

Farrell, L J. \& Barrett, P.M., 2007, 'Prevention of childhood emotional disorders: Reducing the burden of suffering associated with anxiety and depression', Child and Adolescent Mental Health 12(2), 58-65. http://dx.doi.org/10.1111/j.14753588.2006.00430.x

George, D. \& Mallery, P., 2006, SPSS for Windows. Step By step, 6th edn., Allyn and Bacon, Boston.

Goodman, R., 1997, 'The Strengths and Difficulties Questionnaire: A research note', Journal of Child Psychology and Psychiatry 38(5), 581-586. http://dx.doi. org/10.1111/j.1469-7610.1997.tb01545.x

Goodman, R., Ford, T., Simmons, H., Gatward, R. \& Meltzer, H., 2003, 'Using the Strengths and Difficulties Questionnaire (SDQ) to screen for child psychiatric
disorders in a community sample', International Review of Psychiatry 15(1-2), 166-172. http://dx.doi.org/10.1080/0954026021000046128

Goodman, R., Meltzer, H. \& Bailey, V., 1998, 'The Strengths and Difficulties Questionnaire: A pilot study on the validity of the self-report version', European
Child and Adolescent Psychiatry 7(3), 125-130. http://dx.doi.org/10.1007/ Shild and Ado

Goodman, R., Renfrew, D. \& Mullick, M., 2000, ‘Predicting type of psychiatric disorder from Strengths and Difficulties Questionnaire (SDQ) scores in child mental
health clinics in London and Dhaka', European Child and Adolescent Psychiatry health clinics in London and Dhaka', European Child and
9(2), 129-134. http://dx.doi.org/10.1007/s007870050008

Gullone, E., 1996, 'Normal fear in people with a physical or intellectual disability', Clinical Psychology Review 16(8), 689-706. http://dx.doi.org/10.1016/S0272 Clinical Psychology

Hartley, S. \& Muhit, M., 2003, Using qualitative research methods for disability research in majority world countries', Asia Pacific Rehabilitation Journal 14(2) research 114.

Heiervang, E.M., Stormark, K., Lundervold, A.J., Heimann, M., Goodman, R., Posserud, M., et al., 2007, 'Psychiatric disorders in Norwegian 8-to10-year-olds: An epidemiological survey of prevalence, risk factors and service use', Journal of the American Academy of Child and Adolescent Psychiatry 46(4), 438-447. http:// American Academy of Child and Adolescent $P$
dx.doi.org/10.1097/chi.0b013e31803062bf

Kazden, A.E., 1996, 'Dropping out of child psychotherapy: Issues for research and implications for practice', Clinical Child Psychology and Psychiatry 1(1), 133-156. implications for practice', Clinical Child Psychology

Kendall, P.C., 1990, The coping cat workbook, Temple University, Merion Station.

Kendall, P.C., 1993, 'Cognitive-behavioural therapies with youth: guiding theory, current status, and emerging developments', Journal of Consulting and Clinical Psychology 61(2), 235-247. http://dx.doi.org/10.1037/0022-006X.61.2.235

King, N., Gullone, E. \& Stafford, C., 1990, Fears in visually impaired and normally sighted children and adolescents', Journal of School Psychology 28(3), 225-231. $\mathrm{http}: / / \mathrm{dx}$.doi.org/10.1016/0022-4405(90)90013-W

Last, C.G., Perrin, S., Hersen, M. \& Kazdin, A.E., 1996, 'A prospective study of childhood anxiety disorders', Journal of the American Academy of Child and Adolescent Psychiatry 35(11), 1502-1510. http://dx.doi.org/10.1097/00004583-199611000 00019

Le Roux, M.C., 2013, 'Die effek van 'n troeteldier-ondersteunde leesprogram op die leesvaardighede van graad 3 -kinders in ' $n$ Wes-Kaapse laerskool', PhD thesis, University of Stellenbosch.

Lowry-Webster, H.M., Barrett, P.M. \& Dadds, M.R., 2001, 'A universal prevention trial of anxiety and depressive symptomatology in childhood: Preliminary data from an Australian study', Behaviour Change 18(1), 36-50. http://dx.doi.org/10.1375/ bech.18.1.36

Lowry-Webster, H.M., Barett, P.M. \& Lock, S., 2003, 'A universal prevention trial of anxiety symptomology during childhood: Results at 1-year follow-up', Behaviour Change 20(1), 25-43. http://dx.doi.org/10.1375/bech.20.1.25.24843
Loxton, H.S., Visagie, L.S. \& Ollendick, T.H., 2012, 'Assessing the fears of children with varying degrees of visual impairment', paper presented at the 30th International Congress of Psychology, Cape Town, South Africa, July, 2012.

Lyner-Cleophas, M., Swart, E., Chaitaka, T. \& Bell, D., 2014, 'Increasing access into higher education: Insights from the 2011 African Network on Evidence-to-Action on Disability Symposium - Education Commission', African Journal of Disability 3(2), Art. \#78, 3 pages. http://dx.doi.org/10.4102/ajod.v3i2.78

Mash, E.J. \& Wolf, D.A., 2005, Abnormal child psychology, Thompson Wadsworth, Belmont.

Matson, J.L., Manikam, R., Heinze, A. \& Kapperman, G., 1986, 'Anxiety in visually handicapped children and youth', Journal of Clinical Self Psychology 15(4), 356-359. http://dx.doi.org/10.1207/s15374424jccp1504_12

McArdle, P., Prosser, J. \& Kolvin, I., 2004, 'Prevalence of psychiatric disorder: With and without psychosocial impairment', European Child and Adolescent Psychiatry 13(6), 347-353. http://dx.doi.org/10.1007/s00787-004-0367-1

Messer, S.C. \& Beidel, D.C., 1994, 'Psychosocial correlates of childhood anxiety disorders', Journal of the American Academy of Child and Adolescent Psychiatry 93(7), 975-983. http://dx.doi.org/10.1097/00004583-199409000-00007

Mostert, J.J., 2007, 'Pilot study of the effectiveness of the FRIENDS-Programme in a South African sample', Masters thesis, University of Stellenbosch.

Mostert, J. \& Loxton, H., 2008, 'Exploring the effectiveness of the FRIENDS Programme in reducing anxiety symptoms amongst South African children', Behaviour Change 25(2), 85-96. http://dx.doi.org/10.1375/bech.25.2.85

Motoca, L.M., Williams, S. \& Silverman, W.K., 2012, 'Social skills as a mediator between anxiety symptoms and peer interactions among children and adolescents', Journal of Clinical Child and Adolescent Psychology 41(3), 329-336. http://dx.doi.org/10. 1080/15374416.2012.668843

Mullick, M.S.I. \& Goodman, R., 2005, 'The prevalence of psychiatric disorders among 5-10 year olds in rural, urban and slum areas in Bangladesh', Psychiatry and Psychiatric Epidemiology 40(8), 663-671. http://dx.doi.org/10.1007/s00127-0050939-5

Muris, P., 2001, 'A brief questionnaire for measuring self-efficacy in youths', Journal of Psychopathology and Behavioural Assessment 23(3), 145-149. http://dx.doi. org/10.1023/A:1010961119608

Muris, P., Loxton, H., Neumann, A., Du Plessis, M., King, N. \& Ollendick, T., 2006 'DSM-defined anxiety disorders in South African youths: Their assessment and relationship with perceived parental rearing behaviours', Behaviour Research and Therapy 44(6), 883-896. http://dx.doi.org/10.1016/j.brat.2005.06.002

Muris, P., Meesters, C. \& Schouten, E., 2002, 'A brief questionnaire of DSM-IVdefined anxiety and depression symptoms among children', Clinical Psychology \& Psychotherapy 9(6), 430-442.

Muris, P., Schmidt, H., Engelbrecht, P. \& Perold, M., 2002, 'DSM-IV-defined anxiety disorder symptoms in South African children', Journal of the American Academy of Child and Adolescent Psychiatry 41(11), 1360-1368. http://dx.doi. org/10.1097/00004583-200211000-00018

Nevid, J.S., Rathus, S.A. \& Green, B., 2000, Abnormal psychology in a changing world, 4th edn., Prentice Hall, New Jersey.

Olfsen, M., Gameroff, M.J., Marcus, S.C. \& Waslick, B.D., 2003, 'Outpatient treatment in child and adolescent depression in the United States', Archives of Psychiatry 60(12), 1236-1242. http://dx.doi.org/10.1001/archpsyc.60.12.1236

Ollendick, T.H. \& King, N.J., 1998, 'Empirically supported treatments for children with phobic and anxiety disorders: Current status', Journal of Clinical and Child Psychology 27(2), 156-167. http://dx.doi.org/10.1207/s15374424jccp2702_3

Ollendick, T.H., Matson, J.L. \& Helsel, W.J., 1985, 'Fears in visually impaired and normally sighted youths', Behaviour Research and Therapy 23(3), 375-378. http:// dx.doi.org/10.1016/0005-7967(85)90017-8

Petersen, D.J., Bilenberg, N., Hoerder, K. \& Gillberg, C., 2006, 'The population prevalence of child psychiatric disorders in Danish 8-to-9-year-old children', European Child and Adolescent Psychiatry 15(2), 71-78. http://dx.doi. org/10.1007/s00787-006-0488-9

Philander, J.H., 2007, 'The development and evaluation of a pilot school-based programme for prevention of HIV/Aids among visually impaired and blind South African adolescents', PhD thesis, University of Stellenbosch.

Pina, A.A. \& Silverman, W.K., 2004, 'Clinical phenomenology, somatic symptoms, and distress in Hispanic/Latino and Euro-American youths with anxiety disorders', Journal of Clinical Child and Adolescent Psychology 33, 227-236. http://dx.doi. org/10.1207/s15374424jccp3302_3

Pina, A.A., Silverman, W.K., Weems, C.F., Kurtines, W.M. \& Goldman M.L., 2003 'A comparison of completers and noncompleters of exposure-based cognitive and behavioural treatment for phobic and anxiety disorders in youth' Journal of Consulting and Clinical Psychology 71(4), 701-705. http://dx.doi. org/10.1037/0022-006X.71.4.701

Rapee, R.M. \& Barlow, D.H., 1993, 'Generalised anxiety disorder, panic disorder, and the phobias', in P.G. Suther \& H.E. Adams (eds.), Comprehensive handbook for psychopathology, 2nd edn., Plenum, New York. http://dx.doi.org/10.1007/978-14615-3008-4_6

Rapee, R.M., Lyneham, H.J., Schniering, C.A., Wuthrich, V., Abbott, M.J., Hudson, J.L., et al., 2006, The Cool Kids ${ }^{\circ}$ child and adolescent programme therapist manual, Macquarie University, Sydney.

Rey, Y., Marin, C. \& Silverman, W.K., 2011, 'Failures in cognitive-behavior therapy for children', Journal of Clinical Psychology 67(11), 1140-1150. http://dx.doi. org/10.1002/jclp.20848

Sacks, S.Z., Lueck, A.H., Corn, A.L. \& Erin, J.N., 2006, 'Supporting the social and emotional needs of students with low vision to promote academic and social 
success', viewed 17 September 2012, from http://lowvision.aerbvi.org/modules. php?name $=$ News $\&$ file $=$ article $\&$ sid $=38$

Silverman, W.K., 2011, 'Fears and phobias', in G. P Koocher \& A.M. La Greca (eds.), The parents' guide to psychological first aid, Oxford University Press, New York.

Silverman, W.K. \& Kurtines, W.M., 1996, Anxiety and phobic disorders: A pragmatic approach, Plenum Press, New York. http://dx.doi.org/10.1007/978-1-4757-9212-6

Silverman, W.K., Pina, A.A. \& Viswesvaran, C., 2008, 'Evidence-based psychosocial treatments for phobic and anxiety disorders in children and adolescents', Journal of Clinical Child and Adolescent Psychology 37(1), 105-130. http://dx.doi. org/10.1080/15374410701818293

Stallard, P., 2002, Think good-feel good: A cognitive behaviour therapy workbook for young people, John Wiley, Chichester.

Stallard, P., Simpson, N., Anderson, S., Hibbert, S. \& Osborn, C., 2007, 'The FRIENDS emotional health programme: Initial findings from a school-based project', Child
and Adolescent Mental Health $12(21), 32-37$. http://dx.doi.org/10.1111/j.1475and Adolescent Mento

Van Leeuwen, K., Meerschaert, T., Bosmans, G., de Medts, L. \& Braet, C., 2006, 'The Strengths and Difficulties Questionnaire in a community sample of young children in Flande', European Journal of Psychological Assessment 22(3), 189-187. http:// dx.doi.org/10.1027/1015-5759.22.3.189

Visagie, L. \& Loxton, H., 2014, 'Child-friendly procedures and accommodations for the use of a self-report fear survey with children who have visual impairments:
Reflections on a South African case study', British Journal of Visual Impairment 32(3), 179-190. http://dx.doi.org/10.1177/0264619614535373

Visagie, L., Loxton, H., Ollendick, T.H. \& Steel, H.R., 2013, 'Comparing fears in South African children with and without visual impairments', Journal of Visual Impairment and Blindness 107(3), 193-205.

Weems, C.F. \& Silverman, W.K., 2013, 'Anxiety disorders', in T.P. Beauchaine \& S.P. Hinshaw (eds.), Child and adolescent psychopathology, 2nd edn., John Wiley \& Sons, New York.

Weimer, S.A. \& Kratochwill, T.R., 1991, 'Fears of visually impaired children', Journal of Visual Impairment and Blindness 85(3), 118-124.

Weist, M.D., 1999, 'Challenges and opportunities in expanded school mental health', Clinical Psychology Review 19(2), 131-135. http://dx.doi.org/10.1016/s0272 7358(98)00068-3

Wilhelm, J.G., 1989, 'Fear and anxiety in low vision and totally blind children', Education of the Visually Handicapped 20, 163-172.

World Health Organization, 2000, Preventing blindness in children, report of a WHO/ IAPB scientific meeting, viewed 11 February 2009, from http://www.uniteforsight. org/eye stats.php

World Health Organization, 2004, Prevention of mental disorders: Effective interventions and policy options, Geneva, viewed 08 November 2012, from http:// www.who.int/entity/mental_health/evidence/prevention_of mental_disorders sr.pdf 